\title{
NOTES
}

\section{British Medical Association}

\section{Annual Congress, 1953}

At the 121st Annual Congress of the B.M.A., held in Cardiff, J. W. Tudor Thomas was installed as President on July 13, 1953. It will be recalled that only five ophthalmologists-Reeve (Toronto); Snell (Sheffield), Harvey Smith (Winnipeg), Sir James Barrett (Melbourne), and Sichel (Capetown)-have previously been honoured with the presidency of the Association, and Tudor Thomas's year falls exactly 100 years after the first occasion when the Annual Meeting was held in Wales (Swansea, 1853). Charles Hastings, the founder of the Association, once enjoined his colleagues to serve "with head, and heart, and hand "; and this phrase was a happy choice for the title of Mr. Tudor Thomas's presidential address, which ranged widely over the field of general medicine, as well as dealing with advances in ophthalmology.

The President's Reception was held at the National Museum of Wales. On this occasion, and in the course of their numerous other engagements throughout the Congress, Mr. and Mrs. Tudor Thomas communicated an atmosphere of informality and individual welcome. He presided with a distinction which was rendered all the more effective by the support of his charming lady.

Mr. Tudor Thomas also found time to attend part of the meeting of the Section of Ophthalmology, where two subjects were discussed. Mr. G. I. Scott (Edinburgh) and Dr. Leonard Howells (Cardiff) gave opening papers on "The Ocular Complications of Diabetes ", and were followed by Mr. A. B. Nutt (Sheffield). The other subject, "The Scope of Corneal Graft Surgery", was opened by Mr. B. W. Rycroft (London), and subsequent speakers were Mr. E. C. Zorab (Southampton), Mr. J. Ayoub (London), and Mr. A. G. Leigh (London).

The officers of the Section were:

PRESIDENT: J. H. Doggart (London).

Vice-Presidents: Rupert J. Parry (Cardiff), Roy Thomas (Swansea), Eugene Wolff (London); Honorary Secretaries: Bernard Gluck (Cardiff), A. J. B. Goldsmith (London).

\section{International Congress oe Ophthalmology, 1954}

READERS of the Journal will recall from the minutes of the International Council published in our August issue that this body recommended that the XVII International Congress should be extended in scope and time, the suggestion being that it should open in Montreal on September 10,1954, and that Congressists should travel from that city on September 12 to New York, where meetings will be continued until September 17. The following week the Annual meeting of the American Academy of Ophthalmology and Otolaryngology will also be held in New York. Final particulars of these arrangements will be published in the immediate future by the Executive Committee of the Congress in the U.S.A.

Finance.-In order to help those who would find it difficult to attend the Congress for financial reasons, two potential sources of monèy are available:

(a) The Faculty of Ophthalmologists has set aside a fund in sterling for financial assistance in this respect. A sub-committee has been set up to recommend to the Faculty the allocation of this money; those wishing to make application should do so to Mr. Frank Law at 36, Devonshire Place, London, S.W.1. Such applicants should be of British nationality. 